\title{
Silver assisted crack healing in SiC
}

DOI:

10.1016/j.actamat.2015.11.052

\section{Document Version}

Final published version

Link to publication record in Manchester Research Explorer

\section{Citation for published version (APA):}

Geng, X., Yang, F., Chen, Y., Lu, X., Zhong, X., \& Xiao, P. (2016). Silver assisted crack healing in SiC. Acta Materialia, 105(2), 121-129. https://doi.org/10.1016/j.actamat.2015.11.052

\section{Published in:}

Acta Materialia

\section{Citing this paper}

Please note that where the full-text provided on Manchester Research Explorer is the Author Accepted Manuscript or Proof version this may differ from the final Published version. If citing, it is advised that you check and use the publisher's definitive version.

\section{General rights}

Copyright and moral rights for the publications made accessible in the Research Explorer are retained by the authors and/or other copyright owners and it is a condition of accessing publications that users recognise and abide by the legal requirements associated with these rights.

\section{Takedown policy}

If you believe that this document breaches copyright please refer to the University of Manchester's Takedown Procedures [http://man.ac.uk/04Y6Bo] or contact uml.scholarlycommunications@manchester.ac.uk providing relevant details, so we can investigate your claim.

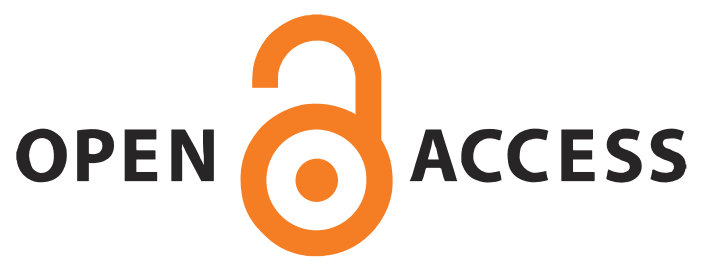


Full length article

\title{
Silver assisted crack healing in SiC
}

\author{
Xin Geng a, b, *, Fan Yang a , Yiqiang Chen ${ }^{\text {a, c }}$, Xiaoxiao Lu ${ }^{a}$, Xiangli Zhong ${ }^{\text {a }}$, Ping Xiao ${ }^{\text {a, }{ }^{* *}}$ \\ ${ }^{a}$ Materials Science Centre, School of Materials, The University of Manchester, Manchester M13 9PL, UK \\ ${ }^{\mathrm{b}}$ School of Materials Science and Engineering, Harbin Institute of Technology, Harbin 150001, People's Republic of China \\ ${ }^{\mathrm{c}}$ The Department of Materials Science and Engineering, Monash University, Clayton, VIC 3800, Australia
}

\section{A R T I C L E I N F O}

Article history:

Received 14 October 2015

Received in revised form

20 November 2015

Accepted 27 November 2015

Available online 24 December 2015

Keywords:

Silicon carbide

Silver

Reprecipitation

Crack healing

\begin{abstract}
A B S T R A C T
This paper provides a potential method through a dissolution-precipitation mechanism to achieve crack healing in $\mathrm{SiC}$ by a vacuum heat treatment with $\mathrm{Ag}$ at $1450{ }^{\circ} \mathrm{C}$. The thermodynamic calculations and experimental results confirm that the $\mathrm{Ag}$ reacts with $\mathrm{SiC}$ to form a molten $\mathrm{Ag}-\mathrm{Si}$ alloy and carbon, which accelerates material transport in $\mathrm{SiC}$, and then by reaction between the $\mathrm{Ag}-\mathrm{Si}$ and carbon, a new $\mathrm{SiC}$ is formed and fills inside the cracks and Vickers indentation impressions to achieve crack healing in SiC. The depth recovery ratio of the indentation is $\sim 60 \%$. The cracks underneath the indentation break into a row of isolated nodules, which is driven by reducing the interfacial energy between $\mathrm{SiC}$ and the $\mathrm{Ag}-\mathrm{Si}$ alloy.
\end{abstract}

() 2015 Acta Materialia Inc. Published by Elsevier Ltd. All rights reserved.

\section{Introduction}

Silicon carbide $(\mathrm{SiC})$ and its composites are important high temperature structural materials for gas turbines, and as nuclear fuel cladding materials, due to their superior mechanical properties (strength, hardness, and Young's modulus), low creep resistance at high temperature, low thermal expansion, good thermo-chemical stability and excellent irradiation tolerance property (low volumetric swelling of $0.7 \%$ after neutron irradiation at $1200^{\circ} \mathrm{C}$ ) [1-3]. However, it is susceptible to cracks caused by machining, friction, overloading, fatigue, etc.. Therefore, for its application at high temperature, $\mathrm{SiC}$ is required to maintain its structural integrity to improve the reliability, which raises an interest in the self-healing of the cracks.

Healing of cracks in $\mathrm{SiC}$ could be achieved by oxidation. Lange first reported an oxidation-induced crack healing in $\mathrm{SiC}$ at $1400{ }^{\circ} \mathrm{C}$ [4]. Under a dry air atmosphere, $\mathrm{SiC}$ reacts with oxygen $\left(\mathrm{O}_{2}\right)$ to form amorphous silica $\left(\mathrm{SiO}_{2}\right)$ and carbon monoxide $(\mathrm{CO})$ :

\footnotetext{
* Corresponding author. School of Materials Science and Engineering, Harbin Institute of Technology, Harbin 150001, People's Republic of China.

** Corresponding author. Materials Science Centre, School of Materials, The University of Manchester, Manchester M13 9PL, UK.

E-mail addresses: gengxin333@gmail.com (X. Geng), p.xiao@manchester.ac.uk (P. Xiao).
}

$$
\mathrm{SiC}(\mathrm{s})+\frac{3}{2} \mathrm{O}_{2}(\mathrm{~s})=\mathrm{SiO}_{2}(l)+\mathrm{CO}(\mathrm{g})
$$

Healing of cracks is achieved due to not only the redistribution by the viscous flow of the glass phase, but also the volume expansion from $\mathrm{SiC}$ to $\mathrm{SiO}_{2}$. The strength of $\mathrm{SiC}$ was reported to be fully recovered at room temperature [5-7]. However, it dropped dramatically to only half of its room temperature value at $600{ }^{\circ} \mathrm{C}$ [6] due to the softening of the glass phase $\mathrm{SiO}_{2}$ at high temperatures [8]. Moreover, it should be pointed out that the oxidation method for crack healing in $\mathrm{SiC}$ is not applicable in the presence of water vapor, i.e., under the complex combustion environment for hightemperature turbine engines, as the water vapor causes volatility of $\mathrm{SiO}_{2}$ by forming various gaseous species, e.g., $\mathrm{Si}(\mathrm{OH})_{4}, \mathrm{SiO}(\mathrm{OH})_{2}$, $\mathrm{SiO}(\mathrm{OH})$, etc. [9].

Re-sintering is another major crack healing mechanism for ceramics, in particular, oxide ceramics, in which cracks are healed through solid diffusion [10-13]. The required temperature to heal the cracks needs to exceed $0.7-0.9$ of the melting point of single crystals or the sintering temperature of polycrystalline ceramics to induce grain growth (sapphire (single crystal $\mathrm{Al}_{2} \mathrm{O}_{3}$ ) $\geq 1800{ }^{\circ} \mathrm{C}$, polycrystalline $\mathrm{Al}_{2} \mathrm{O}_{3}>1400{ }^{\circ} \mathrm{C}$ and $\mathrm{MgO}>1600{ }^{\circ} \mathrm{C}$ ) [14-17]. However, this mechanism is hardly applied to $\mathrm{SiC}$ due to the low diffusion coefficients and high activation energies of both $\mathrm{Si}$ and $\mathrm{C}$ even at high temperatures $\left(1800-2350^{\circ} \mathrm{C}\right)$ hindering the required long range $\mathrm{Si}$ and $\mathrm{C}$ atoms transport to heal cracks [18-21].

In this paper, we report a novel method to achieve crack healing 
in $\mathrm{SiC}$ governed by a dissolution-reprecipitation mechanism at a relatively low temperature $\left(1450{ }^{\circ} \mathrm{C}\right)$.

\section{Experimental procedure}

\subsection{Sample preparation}

The fully-dense $\beta$-SiC bulk sample used in this study was provided by the Dow chemical company. It was fabricated by chemical vapor deposition (CVD) with a high purity of $>99.9995 \%$. The sample was cut into specimens with dimensions of $5 \mathrm{~mm} \times 4 \mathrm{~mm} \times 1 \mathrm{~mm}$. One surface of the specimen was polished by standard metallographic procedures to a final polish using $25 \mathrm{~nm}$ colloidal silica suspensions, and then cleaned ultrasonically in water and dried in air. Cracks were generated on the polished surface by a Vickers micro-indenter using a load of $9.8 \mathrm{~N}$ with a dwell time of $10 \mathrm{~s}$ (Duramin microhardness tester, Struers, UK).

Ag powder (Alfa Aesar, A Johnson Matthey Co., Lancashire, UK, $99.9 \%, 0.7-1.3 \mu \mathrm{m})$ was cold pressed into a pellet $(10 \mathrm{~mm}$ in diameter, 3-5 $\mathrm{mm}$ in thickness) under a uniaxial pressure of $100 \mathrm{MPa}$. The Ag pellet was placed on the indented surface of the $\mathrm{SiC}$ specimen and then the $\mathrm{Ag} / \mathrm{SiC}$ couple was subjected to a vacuum heat treatment at $1450{ }^{\circ} \mathrm{C}$ for $48 \mathrm{~h}$ in a tube vacuum furnace (Elite Thermal Systems Ltd, Leicestershire, UK) with a heating and cooling rate of $300{ }^{\circ} \mathrm{C} / \mathrm{h}$. The vacuum level was maintained at $\sim 10^{-5}$ mbar to avoid oxidation of the specimen.

\subsection{Sample characterization}

The microstructures evolution of SiC were observed by a scanning electron microscope (SEM) (FEI Quanta 650, Eindhoven, $8 \mathrm{kV}$, the Netherlands) and a transmission electron microscope (TEM, Tecnaiтм G2 F30 U-TWIN, $300 \mathrm{kV}$, USA) coupled with an energydispersive X-ray spectrometer (EDX). The chemical compositions of the newly formed $\beta-\mathrm{SiC}$ and the $\mathrm{Ag}-\mathrm{Si}$ nodules were quantitatively analyzed using EDX. A TEM sample and the cross-section under the indentation of the $\mathrm{SiC}$ after annealing with $\mathrm{Ag}$ were prepared by a focused ion beam (FIB; FEI Nova 600 Dual Beam System, USA).

The phase compositions were identified by Raman spectroscopy (Renishaw 1000, Gloucestershire, UK; $632.8 \mathrm{~nm}$ line of $\mathrm{He}-\mathrm{Ne}$ laser), and the spectra were obtained from 200 to $4000 \mathrm{~cm}^{-1}$ with a laser beam of about $2 \mu \mathrm{m}$ in diameter.

The depth profiles of the indentation impression along its diagonal direction were measured by a three dimensional noncontact surface mapping profiler (MicroXAM surface mapping microscope, Phase Shift Technologies, USA).

\section{Results}

\subsection{Indentation recovery}

Fig. 1(a) shows that the SiC grains on the polished surface have a typical columnar structure varying from 50 to $150 \mu \mathrm{m}$ in length highlighted by the red dashed lines. Before heat treatment, the indentation impression shows a clear and sharp edge with a length of $\sim 28 \mu \mathrm{m}$ along the diagonal direction (Fig. 1(b)), and radial cracks are generated on the surface with a width of $\sim 200 \mathrm{~nm}$ (Fig. 1(c)).

After vacuum heat treatment with $\mathrm{Ag}$, a significant change in the morphology of the indentation impression is observed in Fig. 1(d). The indentation impression and the cracks are filled with newlyformed grains with fine sizes of $0.8-2 \mu \mathrm{m}$ as shown in Fig. 1(e) and (f). The size of the indent remains almost unchanged, whereas the indent edges become irregular comparing with the sharp and clear edges before heat treatment.
Raman spectra collected from the surface and the indentation impression before and after heat treatment are shown in Fig. 2. Before heat treatment, the Raman spectrum of the un-indented surface (Fig. 2(a), curve I) shows two strong characteristic peaks centered at 796 and $972 \mathrm{~cm}^{-1}$, which are attributed to the first order of transverse optical (TO) and longitudinal optical (LO) phonons of $\beta$-SiC $[22,23]$. Two additional weak peaks centered at 1524 and $1713 \mathrm{~cm}^{-1}$ represent the second-order Raman scattering of $\beta$ $\mathrm{SiC}$ [24-26]. The Raman spectrum of the indented region (Fig. 2(a), curve II) shows broadened peaks centered at below 500, around 600 and within the region from 700 to $1000 \mathrm{~cm}^{-1}$, which are related to the structural damage caused by plastic deformation. This is in agreement with Ref. [27].

After a vacuum heat treatment with $\mathrm{Ag}$, the Raman spectrum collected from the un-indented surface (Fig. 2(b), curve III) shows sharp peaks centered at 1330, 1584, 1618, 2472, 2662 and $3242 \mathrm{~cm}^{-1}$, which are characteristic peaks of graphite [28]. No peaks corresponding to $\beta$-SiC are detected due to a strong signal of carbon in the Raman spectrum. On the contrary, the Raman spectrum of the indentation impression (Fig. 2(b), curve IV) shows not only the characteristic peaks from carbon, but also the two characteristic peaks from $\beta$-SiC.

The indentation impression after heat treatment with $\mathrm{Ag}$ was cross-sectioned along its diagonal by focused ion beam (FIB) milling as shown in Fig. 3(a). The indentation has been recovered by the newly-formed SiC grains. Fig. 3 (b) shows a color contrast of the $\mathrm{SiC}$ grains, due to the distribution of $\mathrm{Ag}$ impurity formed inside the newly-formed $\mathrm{SiC}$, which is confirmed by the TEM analysis and will be discussed in detail in Section 3.2.

The effectiveness of healing was estimated by a recovery ratio, $\delta$, defined as $[29,30]$ :

$\delta=\frac{\left(h_{0}-h_{a}\right)}{h_{0}} \times 100 \%$

where $h_{0}$ and $h_{a}$ are the maximum residual depths of the indentation impression before and after heat treatment with $\mathrm{Ag}$, respectively.

The depth profiles of the Vickers indentations taken along the diagonal direction before and after heat treatment at $1450{ }^{\circ} \mathrm{C}$ are shown in Fig. 4. As shown in Fig. 4(a), after heat treatment with Ag, a significant change in the profilometric profile of the indentation impression could be observed. The maximum residual depth decreases from $2.74 \mu \mathrm{m}$ before heat treatment to $1.07 \mu \mathrm{m}$ after heat treatment. The recovery ratio calculated from Eq. (2) is $61 \%$. For a comparison, one indented $\mathrm{SiC}$ sample was vacuum annealed without $\mathrm{Ag}$ at $1450{ }^{\circ} \mathrm{C}$ for $48 \mathrm{~h}$ (the morphologies of the indentation impressions before and after heat treatment are shown in Fig. S1 in the supplemental materials). The profilometric profiles of the indentation impression before and after heat treatment are almost identical as shown in Fig. 4(b). Therefore the comparison between Fig. 4(a) and (b) confirms the critical role of $\mathrm{Ag}$ in the indentation recovery of $\mathrm{SiC}$.

In conclusion, the above observations indicate that after the vacuum heat treatment of $\mathrm{SiC}$ with $\mathrm{Ag}$, carbon is formed on the surface and inside the indented impression. Moreover, new grains of $\beta$-SiC are formed to fill in the indentation impression and the radial cracks. The recovery ratio is $61.1 \%$.

\subsection{Crack healing}

To reveal the cracks underneath the indentation impression before heat treatment, the fracture surface along the diagonal direction was prepared by a three-point bending test. Fig. 5(a) and (b) show that the length of a median crack in the fracture surface is 


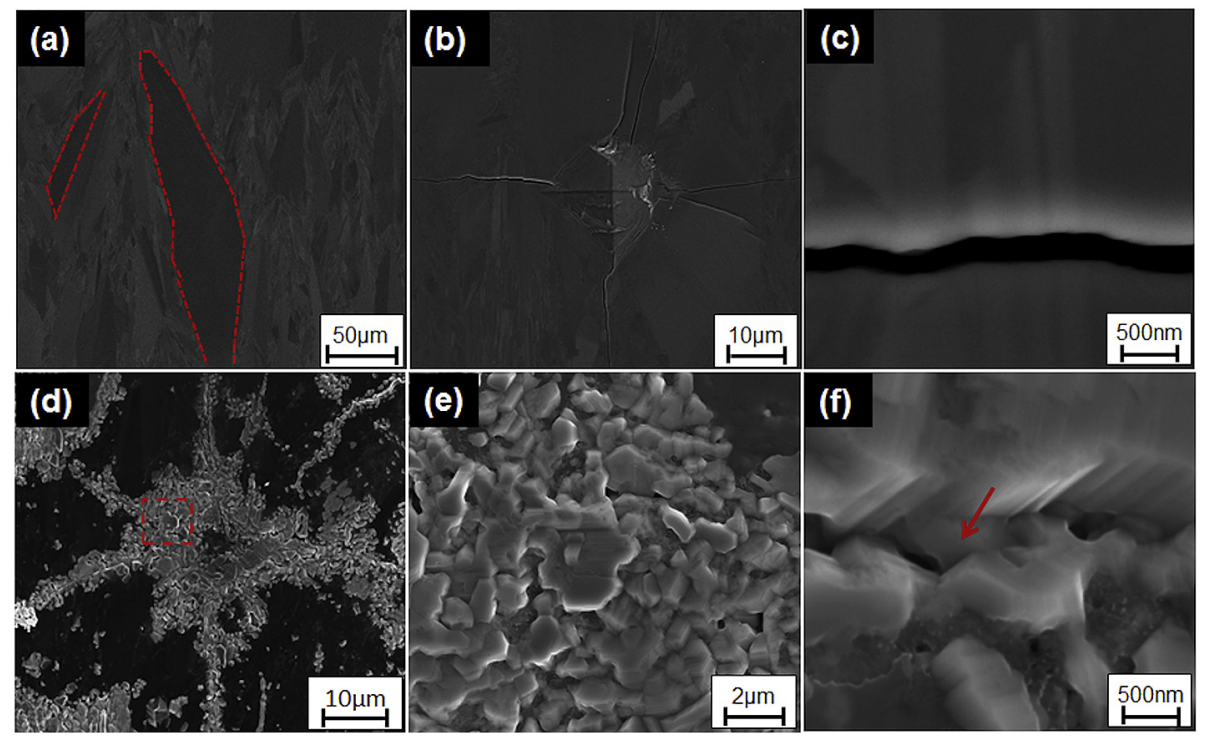

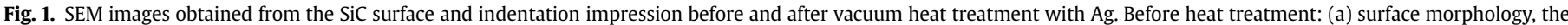

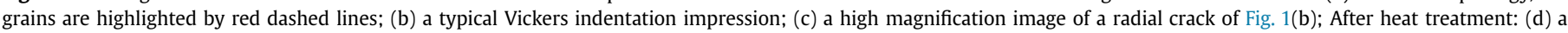

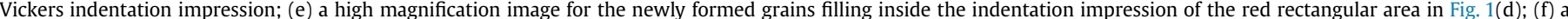

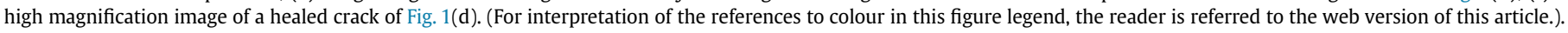
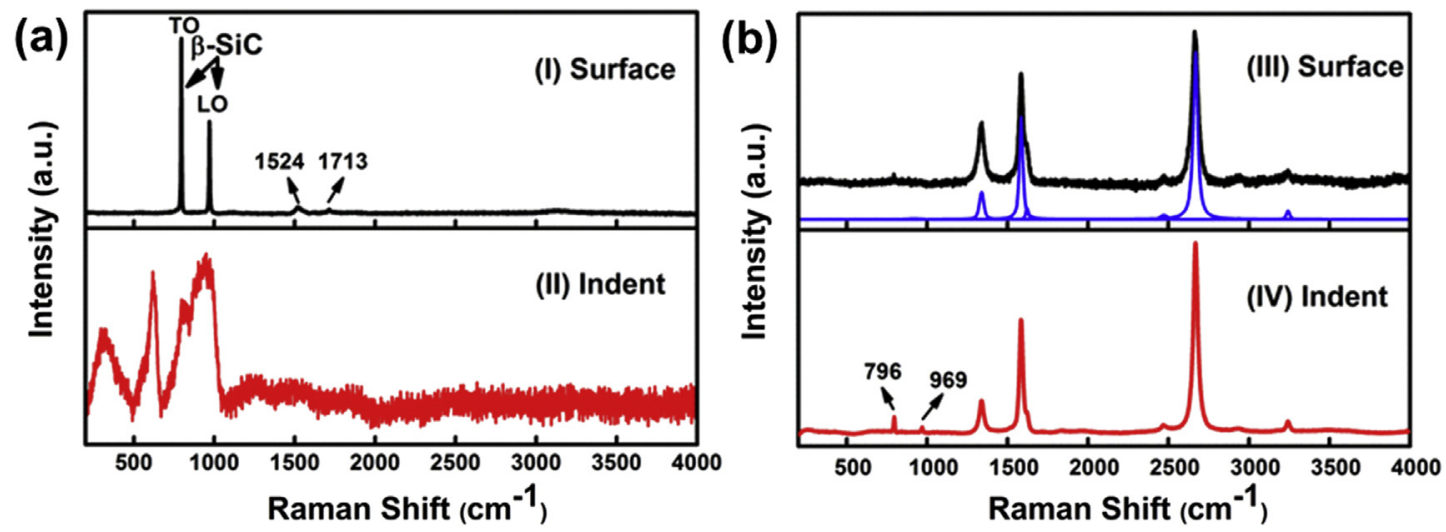

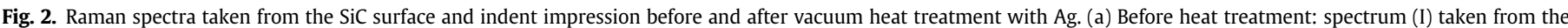

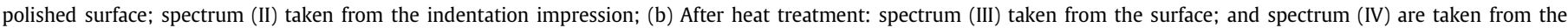
indentation impression.
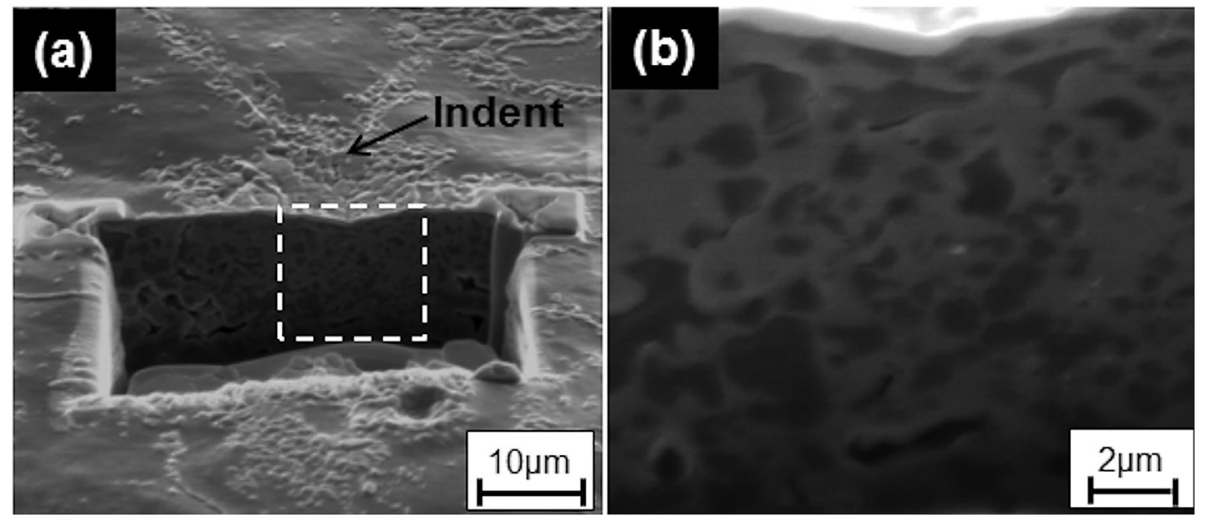

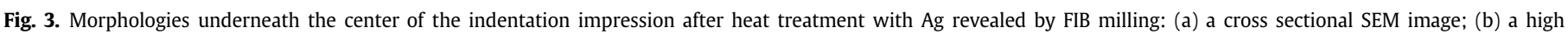
magnification image of the white rectangular area in Fig. 3(a). 

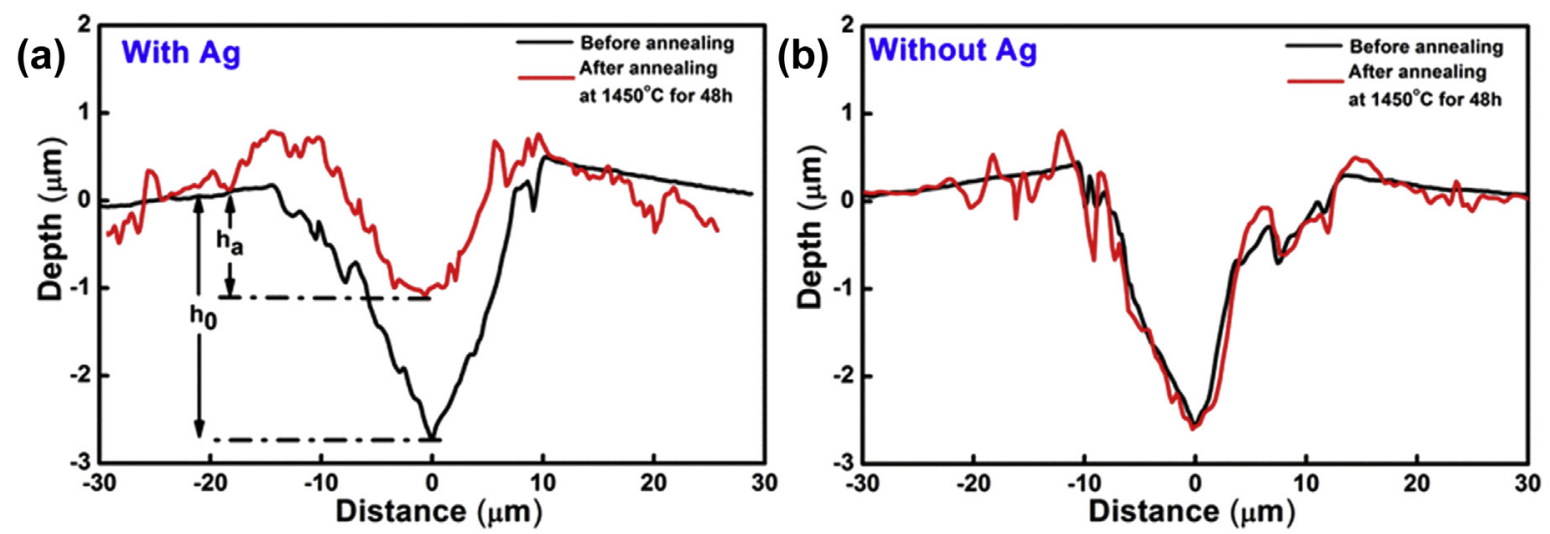

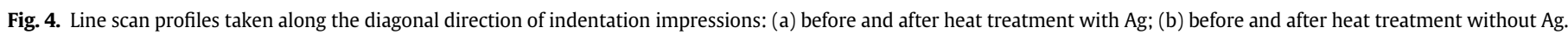
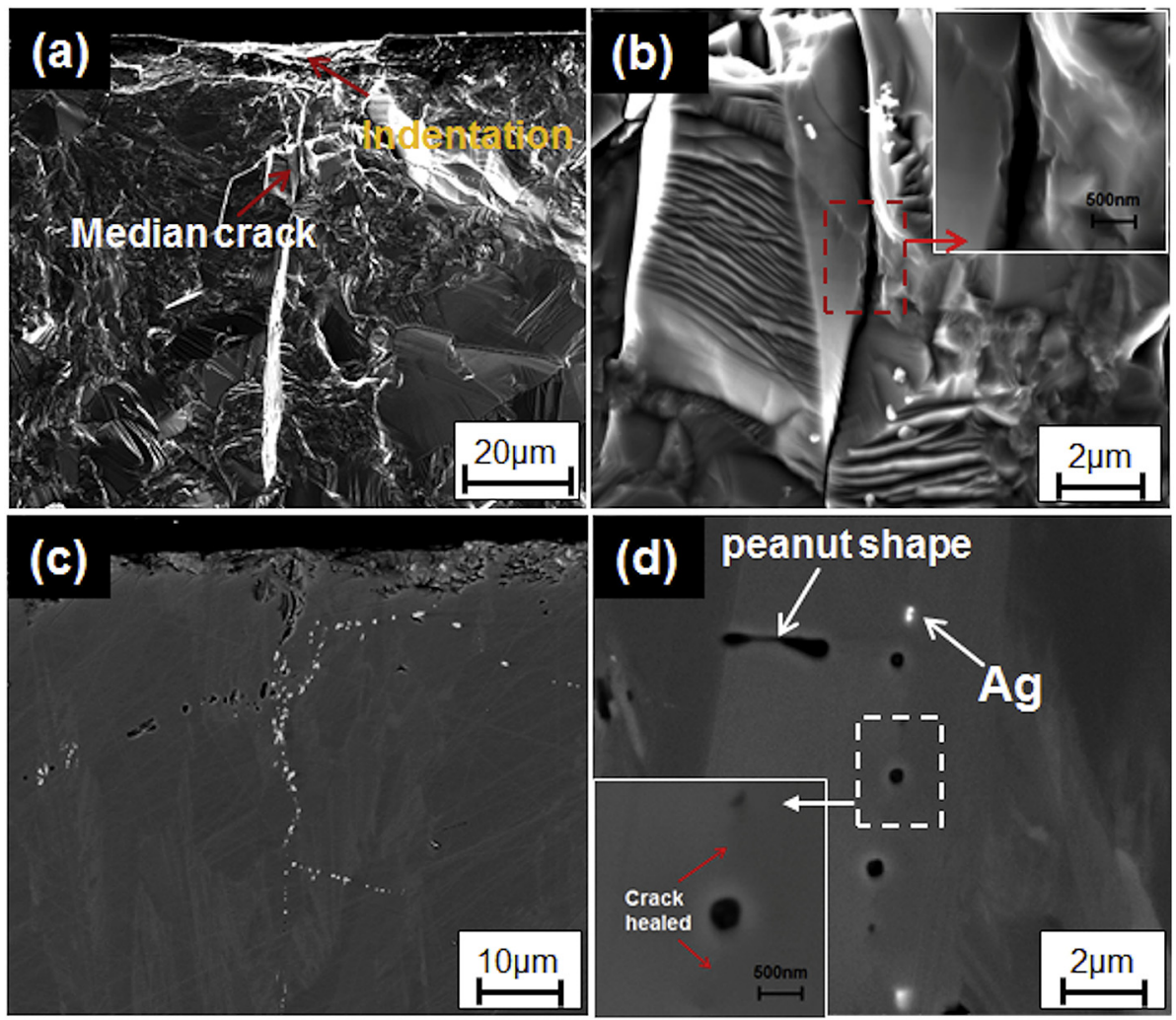

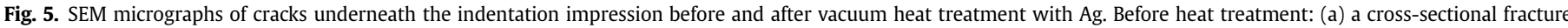

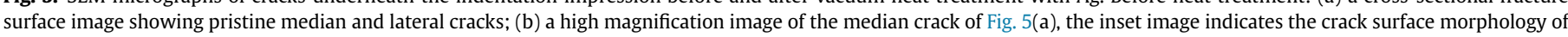

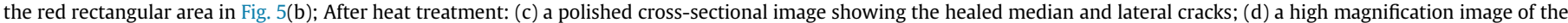

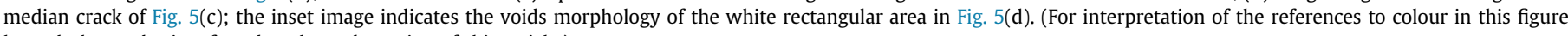
legend, the reader is referred to the web version of this article.).

approximately $80 \mu \mathrm{m}$ and the width is about $500 \mathrm{~nm}$. A high magnification image of the median crack shows that the crack surface is rough (Fig. 5(b)). For a comparison, the cross section of the $\mathrm{SiC}$ sample was carefully polished until the center of the indentation impression after heat treatment with Ag. As shown in Fig. 5(c), the original profiles of the median and the lateral cracks are sketched by discontinuous Ag nodules and voids (voids were formed during the polishing process due to the extrusion or dissolution of Ag by the silica suspension). Fig. 5(d) illustrates that Ag exists in the cracks of SiC with two morphologies: a 'peanut' shape and an isolated spherical shape. A high magnification image of the area near the Ag nodules (voids) shows that the crack has been fully healed (the inset image of Fig. 5(d)). It is worth noticing that the surface inside the voids is smooth compared with the tortuous surface inside the pristine median crack (Fig. 5(d)). At high temperature, the melted $\mathrm{Ag}$ penetrates through the crack and fills the crack gap. The Ag liquid breaks into a row of nodules due to a capillarity-induced shape change to reduce the interfacial energy [12]. In the meantime, the dissolution-reprecipitation process occurs. The gaps between two Ag nodules are filled by newly-formed $\mathrm{SiC}$ grains. This mechanism will be discussed in detail in Section 4.3.

FIB was used to prepare a TEM sample from the healed median crack region on the cross-sectional polished surface (Fig. 6(a)). The TEM sample contains two isolated spherical shape $\mathrm{Ag}-\mathrm{Si}$ nodules. 


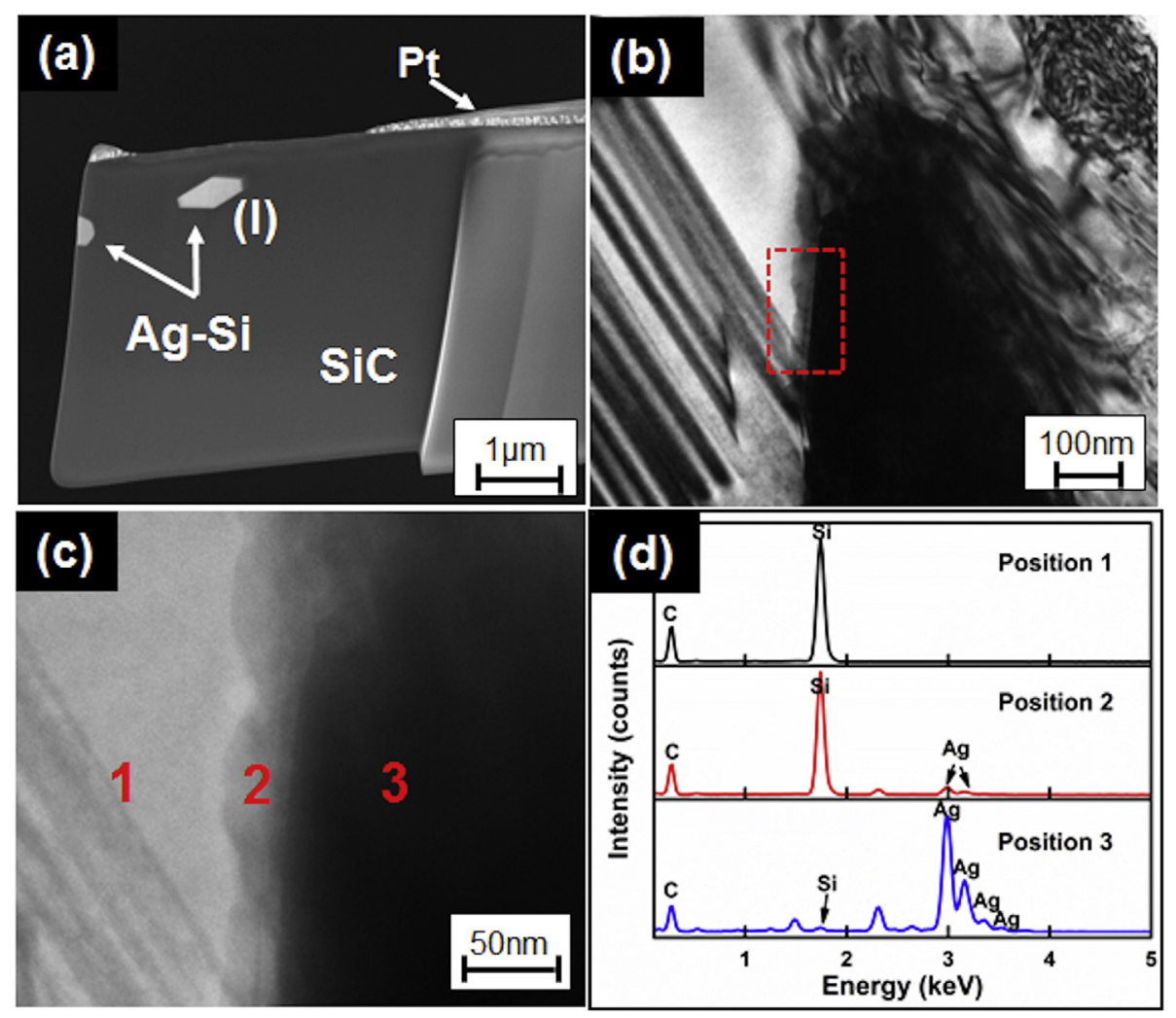

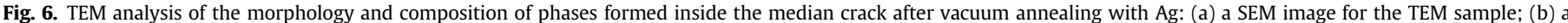

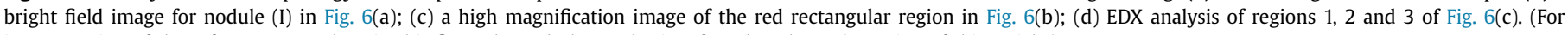
interpretation of the references to colour in this figure legend, the reader is referred to the web version of this article.).

The bright field TEM image of the Ag-Si nodule (I) (Fig. 6(b)) shows that an additional layer is formed between the pristine $\mathrm{SiC}$ and the $\mathrm{Ag}-\mathrm{Si}$ nodule, as illustrated by the color difference among the three regions. Moreover, the interface is smooth between the $\mathrm{Ag}-\mathrm{Si}$ nodule and this newly formed additional layer (Fig. 6(c)), which the newly-formed phase smooths the tortuous pristine crack surface of the SiC. Point EDX analysis (Fig. 6(d)) reveals that the brighter area (position 1) contains only $\mathrm{Si}$ and $\mathrm{C}$, corresponding to the original $\mathrm{SiC}$. The interfacial layer (position 2) contains $\mathrm{Si}, \mathrm{C}$ and $\mathrm{Ag}$, corresponding to the newly-formed $\mathrm{SiC}$. It is confirmed that the contrast difference comes from the Ag impurity dissolved in the newlyformed SiC grains, which is in agreement with the results reported by Sawyer and Page [31]. Moreover, an EDX spectrum of the nodule (position 3 ) indicates that $\mathrm{Si}$ dissolves in the Ag nodule. It should be noted that the electron beam size is sufficiently small $(<1 \mathrm{~nm})$ to guarantee that all the information is collected from the each region without influences from the others.

In summary, cracks underneath the indentation impression of $\mathrm{SiC}$ are healed by breaking up to rows of 'peanut' and isolated spherical shape $\mathrm{Ag}-\mathrm{Si}$ nodules after the vacuum heat treatment with $\mathrm{Ag}$ at $1450{ }^{\circ} \mathrm{C}$. New $\mathrm{SiC}$ is formed to fill the gaps between the nodules in the cracks, and smooth the tortuous crack surface of SiC.

\section{Discussion}

The above observations indicate that after the vacuum heat treatment of $\mathrm{SiC}$ with $\mathrm{Ag}: 1)$ the indentation impression and the cracks are healed by newly-formed $\beta$-SiC grains, and carbon is formed on the surface and on the indented impression; 2) both the 'peanut' and spherical shape of the $\mathrm{Ag}-\mathrm{Si}$ nodules formed and stretched the cracks during the isothermal heat treatment. In the following, thermodynamic and kinetics aspects of cracks healing in $\mathrm{SiC}$ with the assistance by silver (Ag) will be discussed. Firstly, enhancement of material transport $(\mathrm{Si})$ in $\mathrm{SiC}$ achieving crack healing of SiC at low temperature $\left(1450^{\circ} \mathrm{C}\right)$ will be discussed by the thermodynamic calculation of the reaction between $\mathrm{Ag}$ and $\mathrm{SiC}$ (present in Section 4.1). Secondly, the driving force for the indentation recovery by filling with the reprecipitation fine $\beta$-SiC grains is discussed in Section 4.2. Finally, the kinetics model for crack (the median and the lateral cracks) healing and $\mathrm{Ag}-\mathrm{Si}$ alloys nodules evolution behaviors is presented in Section 4.3.

\subsection{Enhancement of material transport in SiC by annealing with Ag}

It is difficult to heal the cracks and recover micro-indentation impressions of $\mathrm{SiC}$ governed by the re-sintering mechanism annealed at low temperature $\left(1450{ }^{\circ} \mathrm{C}\right)$, since the activation energies for $\mathrm{Si}$ or $\mathrm{C}$ self-diffusing through $\mathrm{SiC}$ are high: $>695 \mathrm{~kJ} / \mathrm{mol}$ for $\mathrm{Si}$ and $>562 \mathrm{~kJ} / \mathrm{mol}$ for C $[18-21,32]$. The slow solid state diffusion process cannot satisfy the long range material transport for healing the cracks. In the following, thermodynamic calculation is employed to discuss that the addition of Ag changes the Si transport way from solid diffusion to a liquid $\mathrm{Ag}-\mathrm{Si}$ alloy flow, similar to how silica glass phase filled the cracks in SiC caused by the oxidation process. The liquid $\mathrm{Ag}-\mathrm{Si}$ alloy flow accelerates crack healing process.

Firstly, the liquid of Si cannot be generated spontaneously by purely the decomposition of $\mathrm{SiC}$ as shown in Eq. (3):

$\operatorname{SiC}(s) \rightarrow \operatorname{Si}(l)+C(s)$ 
$\Delta G_{1}=\sum x_{i} \cdot \mu_{i}^{0}=\mu_{S i}^{0}+\mu_{C}^{0}-\mu_{S i C}^{0}$

where $\Delta G_{1}$ is the Gibbs energy of reaction (3); $\mu_{\text {SiC }}^{0}\left(-1.6561 \times 10^{5} \mathrm{~J} /\right.$ $\mathrm{mol}), \mu_{S i}^{0}\left(-7.1517 \times 10^{4} \mathrm{~J} / \mathrm{mol}\right)$ and $\mu_{C}^{0}\left(-3.520 \times 10^{4} \mathrm{~J} / \mathrm{mol}\right)$ are the chemical potential of $\mathrm{SiC}$, Si and $\mathrm{C}$ at $1450{ }^{\circ} \mathrm{C}$. The values are determined by commercial software (Thermo-Calc 4.1, database: NUCL 10).

The positive value of $\Delta \mathrm{G}_{1}=5.89 \times 10^{4} \mathrm{~J}$ confirms that reaction (3) cannot occur spontaneously at $1450{ }^{\circ} \mathrm{C}$.

In contrast, $\mathrm{SiC}$ annealing with $\mathrm{Ag}$ at $1450^{\circ} \mathrm{C}$ helps to form liquid $\mathrm{Ag}-\mathrm{Si}$ alloys. Our previous study has found the following reversible chemical reaction between $\mathrm{Ag}$ and $\mathrm{SiC}$ at $1450{ }^{\circ} \mathrm{C}$ in vacuum [33]:

$(1-\chi) \cdot A g(l)+\chi \cdot \operatorname{SiC}(s) \leftrightarrow A g_{1-\chi} S_{x}(l)+x \cdot C(s)$

where $\mathrm{x}$ represents the mole fraction of silicon (Si) in liquid silversilicon alloys.

According to the silver-silicon phase diagram [34], the experimental temperature $\left(1450{ }^{\circ} \mathrm{C}\right)$ is higher than the melting points of all silver-silicon alloys, which is in the range from 835 to $1414{ }^{\circ} \mathrm{C}$. $\mathrm{Ag}$, in its liquid form, reacts with $\mathrm{SiC}$ at $1450^{\circ} \mathrm{C}$ to form carbon and a $\mathrm{Si}-\mathrm{Ag}$ alloy. Subsequently, reprecipitation of $\beta$-SiC occurs inside the Vickers micro-indentations and heals the cracks. Furthermore, the $\mathrm{Ag}-\mathrm{Si}$ alloy evaporates at high temperature, leaving carbon and new $\mathrm{SiC}$ grains.

Gibbs free energy $\left(\Delta \mathrm{G}_{2}\right)$ of reaction (5) in the right direction is calculated as shown in Eq. (6):

$\Delta G_{2}=\sum x_{i} \cdot \mu_{i}^{0}=\mu_{A g_{(1-x)}-S i_{(x)}}^{0}+x \cdot \mu_{C}^{0}-(1-x) \cdot \mu_{A g}^{0}-x \cdot \mu_{S i C}^{0}$

The regular solution model is employed to derive the chemical potential of the molten $\mathrm{Ag}-\mathrm{Si}$ alloys:

$$
\begin{aligned}
\mu_{A g_{(1-x)}-S i_{(x)}=}^{0} & (1-x) \cdot \mu_{A g}^{0}+x \cdot \mu_{S i}^{0}+R T \cdot\left((1-x) \cdot \ln \alpha_{A g}\right. \\
& \left.+x \cdot \ln \alpha_{S i}\right)
\end{aligned}
$$

where $\alpha_{A g}$ and $\alpha_{S i}$ are the activities of Si and $\mathrm{Ag}$ in a molten $\mathrm{Ag}-\mathrm{Si}$ alloy at the given silicon composition (x). Substituting Eq. (7) in Eq. (6), the expression can hence be written as:

$\Delta G_{2}=x \cdot\left(\mu_{S i}^{0}+\mu_{C}^{0}-\mu_{S i C}^{0}\right)+R T \cdot\left((1-x) \cdot \ln \alpha_{A g}+x \cdot \ln \alpha_{S i}\right)$

The Gibbs energy of the reversible reaction (5) in the right direction can be divided into two terms: $A=\chi \cdot\left(\mu_{S i}^{0}+\mu_{C}^{0}-\mu_{S i C}^{0}\right)$ and $B=R T \cdot\left((1-x) \cdot \ln \alpha_{A g}+x \cdot \ln \alpha_{S i}\right)$;

It is clear that term A represent $x$ multiplied by the Gibbs energy $\left(\Delta G_{1}\right)$ of reaction (3), of which the value is positive. The activities of silver $\left(\alpha_{A g}\right)$ and silicon $\left(\alpha_{S i}\right)$ in molten $\mathrm{Ag}$-Si alloys depending on the silicon mole fraction $(\mathrm{x})$ at $1450{ }^{\circ} \mathrm{C}$ were determined by the Thermo-Calc software (version 4.1 and NUCL 10 database) and plotted in Fig. 7(a), of which the values are in agreement with the experimental values measured by Robinson [35]. It should be noted that the activities of $\mathrm{Ag}\left(\alpha_{A g}\right)$ and $\mathrm{Si}\left(\alpha_{S i}\right)$ are lower than 1 at any composition, where $\ln \alpha_{\mathrm{Ag}}<0$ and $\ln \alpha_{\mathrm{Si}}<0$, therefore, the value of term $B$ is negative and helps to reduce the value of $\Delta G_{2}$. The relationship between $\Delta \mathrm{G}_{2}$ and the silicon mole fraction $(\mathrm{x})$ is shown in Fig. 7(b). The definition of the threshold silicon fraction $\left(\mathrm{m}_{\mathrm{t}}\right)$ is the silicon mole fraction corresponding to $\Delta \mathrm{G}_{2}=0\left(\mathrm{~m}_{\mathrm{t}}=1.203 \mathrm{at} \%\right.$ for Fig. 7(b)). It confirms that annealing with $\mathrm{Ag}$ causes SiC decomposition to liquid $\mathrm{Ag}-\mathrm{Si}$ alloys and carbon for a $\mathrm{Si}$ mole fraction lower than $1.203 \mathrm{at} \%$, and therefore, the molten $\mathrm{Ag}-\mathrm{Si}$ alloys accelerate material transport in SiC compared with solid diffusion.

In the meantime, silver in the $\mathrm{Ag}-\mathrm{Si}$ alloy evaporates during the isothermal heat-treatment process at $1450{ }^{\circ} \mathrm{C}$, which increases the silicon mole fraction in the Ag-Si alloys. When the silicon mole fraction exceeds the threshold silicon fraction value $\left(\mathrm{m}_{\mathrm{t}}=1.203 \mathrm{at}\right.$ $\%$ ), the reaction (5) occurs spontaneously in the reverse direction, new $\beta$-SiC grains are reprecipitated and fill the Vickers microindentations and the cracks by the reaction of $\mathrm{Ag}-\mathrm{Si}$ alloys and carbon.

In conclusion, the dissolution-reprecipitation mechanism governs indentation recovery and cracks healing in SiC by the assistance with $\mathrm{Ag}$ annealed at $1450{ }^{\circ} \mathrm{C}$, due to formation of the molten $\mathrm{Ag}-\mathrm{Si}$ alloys. Moreover, following the direction of thermodynamic calculation of reaction (5), the prerequisites for choosing other metals, which could assist cracks healing in SiC, are summarized below:

(1) The melting points of both metal and metal-Si alloys are low $\left(<1450{ }^{\circ} \mathrm{C}\right)$.

(2) The liquid metals can dissolve an amount of silicon, but do not form an intermetallic compound.

(3) The activities of silicon and metals in the liquid metal-Si alloys are lower than 1.

In the following section, the driving force for the reprecipitation fine $\beta$-SiC grains filling the Vickers micro-indentation will be discussed.

\subsection{SiC reprecipitation for indentation recovery}

The local interface curvature affected the Gibbs energy of SiC, as expressed below [36]:

$\mu_{S i C}=\mu_{S i C}^{0} \pm \gamma \cdot \Omega \cdot \kappa$

where $\mu_{S i C}$ is the Gibbs potential of $\mathrm{SiC}(\mathrm{J} / \mathrm{mol}) ; \mu_{S i C}^{0}$ is the chemical potential of SiC $(\mathrm{J} / \mathrm{mol}) ; \gamma$ is the surface tension of $\mathrm{SiC}\left(\mathrm{J} / \mathrm{m}^{2}\right)$; The surface tension of SiC is $\gamma=3.0-0.546 \times 10^{-3} \mathrm{~T}\left(\mathrm{~J} / \mathrm{m}^{2}, \mathrm{~T}\right.$ is absolute temperature (K)) [37]; $\Omega$ is the $\mathrm{SiC}$ atomic volume $\left(1.25 \times 10^{-2} \mathrm{~m}^{3} /\right.$ mol); ${ }_{\kappa}$ is the local curvature of the SiC surface, ' + ' for the convex surface and '-' for the concave surface.

There are two principle curvatures at each point of the indentation impression: $\kappa_{1}$ corresponding to along the $x-y$ axis and $\kappa_{2}$ is normal to the $x-y$ axis. The mean curvature $\kappa=\kappa_{1}+\kappa_{2}$. It can be considered that a Vickers indentation impression is constituted of a series of thin slice as shown in Fig. 8(a) (slice (I), (II), (III) etc.), where each slice is highlighted by one color. Since the thickness of each slice is thin and can be consider as flat, the curvature $\kappa_{2}$ is 0 . Therefore, the mean curvature $(\kappa)$ corresponding to the surface of each slice equals the curvature $\left(\kappa_{1}\right)$ of the depth profile. The depth profile of the Vickers indentation impression along its diagonal direction has been used as an example to calculate the curvatures (the black line shown in Fig. 8(b)). A ninth-order polynomial function, $f(x)=\sum_{i=0}^{9} p_{i} \cdot x^{i}$, is used to fit this depth profile as shown in the red curve in Fig. $8(\mathrm{~b})$ and the parameters $\left(\mathrm{p}_{\mathrm{i}}\right)$ of this function are determined by commercial software (Matlab R2009a). The curvatures of the fitted depth profile (the red curve in Fig. 8(b)), $\kappa$, along the distance can be calculated using the following equation.

$\kappa=\frac{\left|f^{\prime \prime}(x)\right|}{\left(1+f \prime(x)^{2}\right)^{3 / 2}}$

The relationship between the curvatures of the depth profile of Fig. 8(b) and distance is plotted in Fig. 8(c). The curvature values 

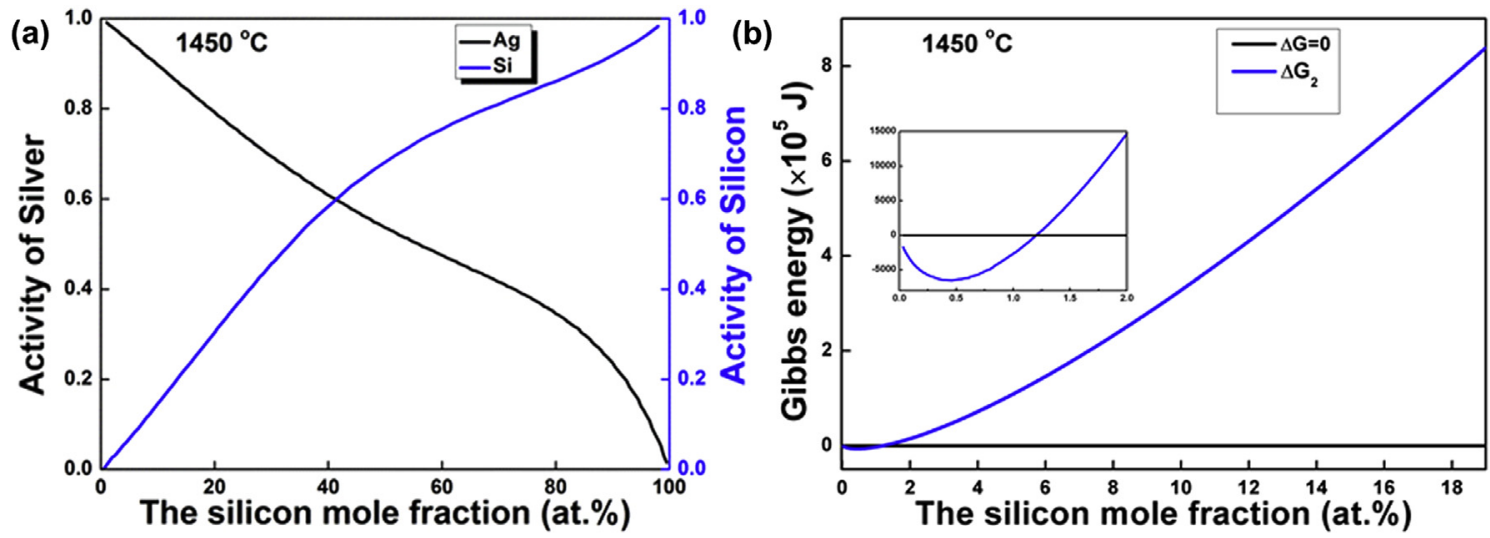

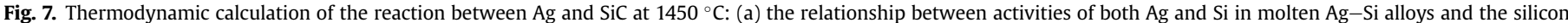
mole fraction; and (b) the relationship between Gibbs energy of the reaction and the silicon mole fraction (x), the inset image indicates an enlarged view for $\mathrm{x}$ from 0 to 2.
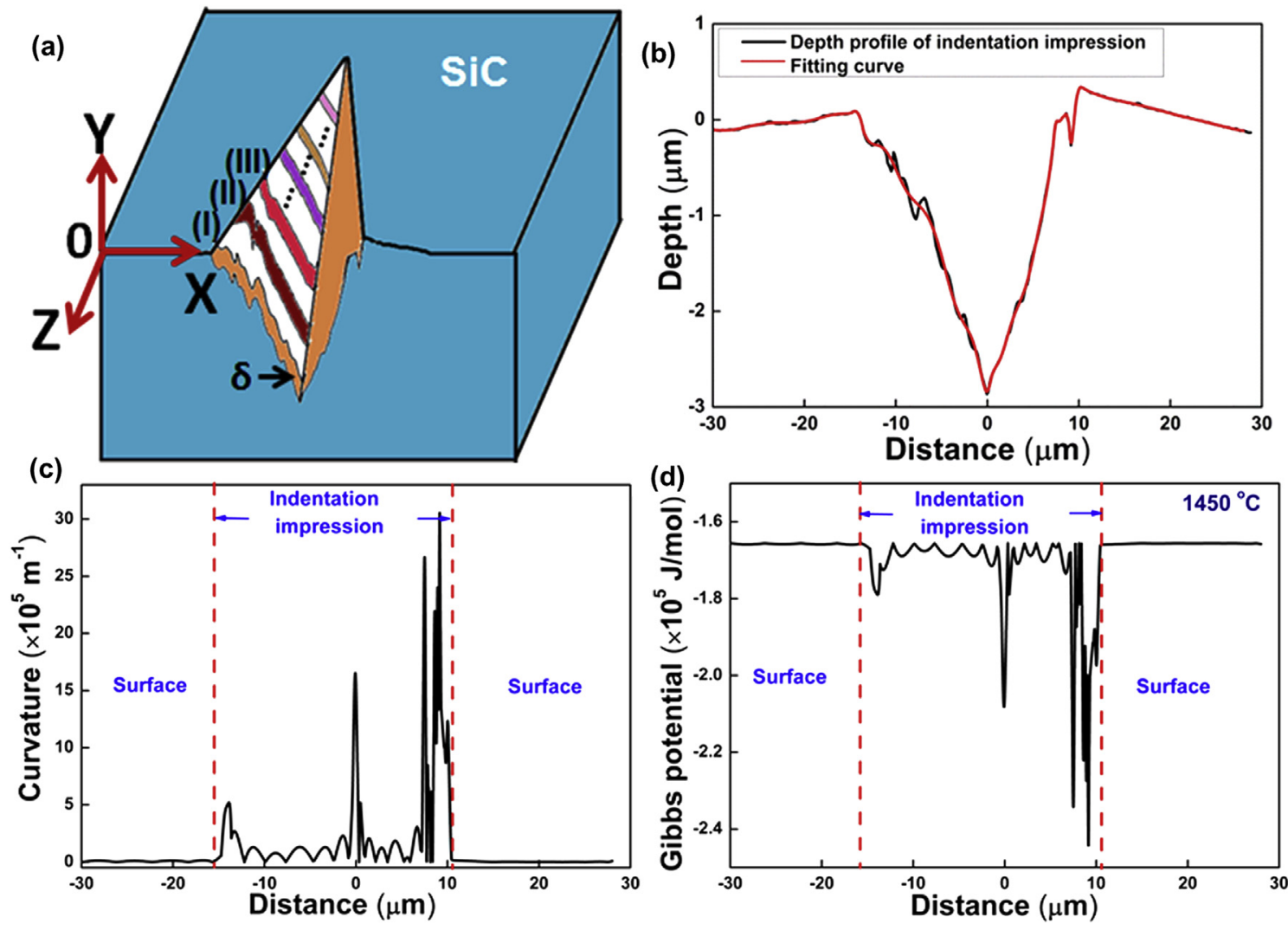

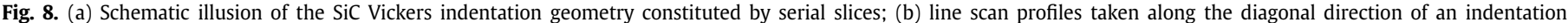

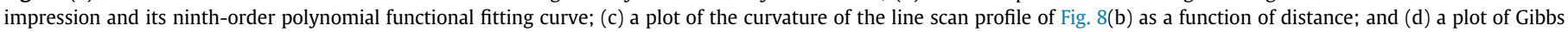
potential of $\mathrm{SiC}$ versus distance.

inside the indentation impression range from 585 to $3 \times 10^{6} \mathrm{~m}^{-1}$ and its values are much larger than them on the surface, especially at the indentation edge and center area. Therefore, the SiC Gibbs potential corresponding to the depth profile of Fig. 8(b) at $1450{ }^{\circ} \mathrm{C}$ calculated by Eq. (9) versus the distance is plotted in Fig. 8(d). This suggests that the Gibbs potential of $\mathrm{SiC}$ inside the indentation impression (concave surface) is less than that on the flat surface.

The Gibbs free energy $\left(\Delta \mathrm{G}_{3}\right)$ of reaction (5) occurring inside the indentation is shown below:

$$
\begin{aligned}
\Delta G_{3}= & x \cdot\left(\mu_{S i}^{0}+\mu_{C}^{0}-\mu_{S i C}^{0}+\gamma \cdot \Omega \cdot \kappa\right)+R T \cdot\left((1-x) \cdot \ln \alpha_{A g}\right. \\
& \left.+x \cdot \ln \alpha_{S i}\right)
\end{aligned}
$$

Fig. 9(a) shows a surface plot of $\Delta G_{3}$ versus silicon mole fraction (x) and distance (flat surface to the indentation impression to flat surface, corresponding to Fig. 8). It suggests that both the silicon mole fraction ( $\mathrm{x}$ ) and curvature affect significantly on the values of $\Delta G_{3}$. The 2-D plot of the threshold silicon fraction $\left(m_{t}\right)$ versus distance is shown in Fig. 9(b), where $\Delta \mathrm{G}_{3}=0$.

Due to the high curvature values of the indentation impression, 

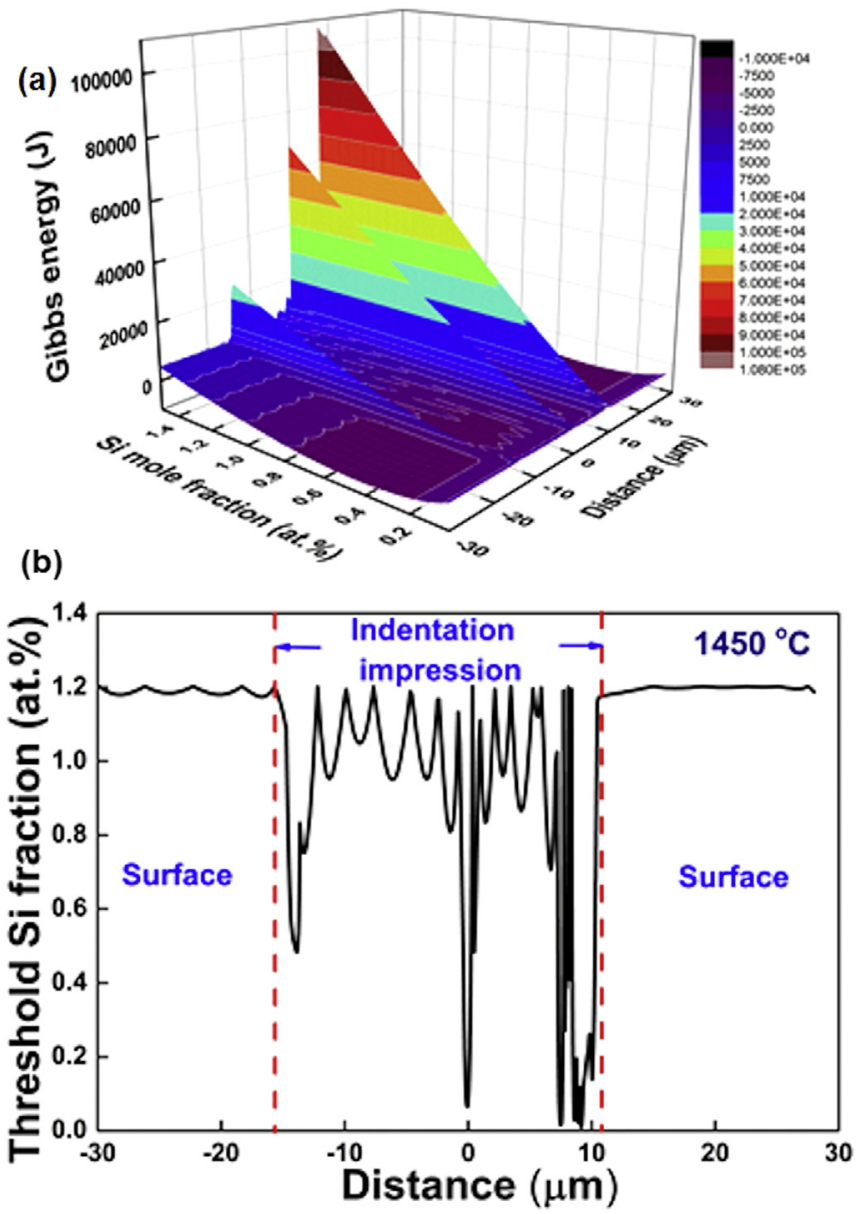

Fig. 9. Thermodynamic calculation of the reaction between $\mathrm{Ag}$ and $\mathrm{SiC}$ Vickers indentation impression at $1450{ }^{\circ} \mathrm{C}$ : (a) plots of Gibbs energy change versus silicon mole fraction (x) and distance; (b) the relationship between the threshold silicon fraction and distance.

the gradient of the threshold silicon fraction values $\left(\mathrm{m}_{\mathrm{t}}\right)$ causes the fine $\beta$-SiC grains to be preferentially reprecipitated inside the indentation impression especially at the edges and center of the indentation. With silver in $\mathrm{Ag}-\mathrm{Si}$ alloys evaporation during the isothermal process, it is easier to reach the threshold silicon fraction values $\left(\mathrm{m}_{\mathrm{t}}\right)$ inside the indentation compared with the flat surface, and then the reversible reaction (5) occurs spontaneously in the reverse direction. This is in agreement with the depth profile result that the height of the indentation impression edge is higher than the height of the flat surface after the vacuum heat-treatment with $\mathrm{Ag}$ (shown in the red curve in Fig. 4(a)).

In summary, the existence of a gradient in the Gibbs potential of $\operatorname{SiC}(\gamma \cdot \Omega \cdot \kappa(\mathrm{J} / \mathrm{mol})$, where the Gibbs potential at the flat surface is higher than the value at the concave surface (the Vickers indentation), drives the SiC transport in the direction from the flat surface region to the indentation impression region by reducing the system Gibbs energy of SiC. Therefore, the driving potential is $\gamma \cdot \Omega \cdot \kappa(\mathrm{J} /$ $\mathrm{mol})$, in a direction from the flat surface to the Vickers indentation impression of $\mathrm{SiC}$.

\subsection{Interfacial tension induced $\mathrm{Ag}-\mathrm{Si}$ nodules inside cracks of SiC}

After the heat-treatment with $\mathrm{Ag}$ at $1450{ }^{\circ} \mathrm{C}$, SEM and TEM micrographs illustrated that the cracks underneath the SiC surface were sketched by both 'peanut' shape and isolated Ag-Si nodules.
The newly-formed $\beta$-SiC not only fully healed the gaps between two Ag-Si nodules, but also created an additional layer between an $\mathrm{Ag}-\mathrm{Si}$ alloy nodule and pristine $\mathrm{SiC}$ crack surface. Similar phenomena that cracks break up into rows of isolated spherical voids are found in $\mathrm{Al}_{2} \mathrm{O}_{3}, \mathrm{MgO}$ and related ceramics by annealing at elevated temperatures [16,17,38,39].

The Plateau-Rayleigh instability theory [40] is employed to explain the mechanism for the evolution of the isolated $\mathrm{Ag}-\mathrm{Si}$ nodules inside the cracks of $\mathrm{SiC}$, and a model is proposed as shown in Fig. 10. Initially, capillarity and gravity forces drive the molten Ag filling in the cracks of SiC (Fig. 10(a)). The 'perturbations' as shown in areas (I) and (II) of Fig. 10(a) are a schematic illustration of a pristine rough median crack surface in SiC as depicted in Fig. 5(a) and (b). In the 'perturbations' areas, the interfacial tension between molten $\mathrm{Ag}$ and $\mathrm{SiC}, \mathbf{F}=\gamma_{\boldsymbol{s} \boldsymbol{L}}$, breaks into two vectors: $\boldsymbol{F}_{\boldsymbol{a}}$ along the crack direction and $\boldsymbol{F}_{\boldsymbol{v}}$ normal to that and points to the molten $\mathrm{Ag}$. Therefore, the normal vector $\boldsymbol{F}_{\boldsymbol{v}}$ "drags" the unstable continuous molten silver inside the crack to form the 'peanut' shape $\mathrm{Ag}-\mathrm{Si}$ alloys nodules as shown in Fig. 10(b). In the meantime, the reaction between molten silver and $\mathrm{SiC}$ occurs and a flux of SiC is transported from the trough to the crest inducing by a gradient of the $\mathrm{SiC}$ Gibbs potential, due to the curvature difference as investigated in Section 4.2. Therefore, the isolated Ag-Si nodules are formed and the cracks between those nodules are fully healed as shown in Fig. 10(c).

In summary, Cracks underneath the $\mathrm{SiC}$ surface tends to break up rows of the isolated spherical $\mathrm{Ag}-\mathrm{Si}$ nodules governed by minimizing interfacial surface. The projected force of interfacial tension between molten $\mathrm{Ag}$ or $\mathrm{Ag}-\mathrm{Si}$ alloys and $\mathrm{SiC}\left(\boldsymbol{F}_{\boldsymbol{v}}\right)$ is the driving force for healing the cracks in SiC. Moreover, this driving force tends to smooth the interface between the SiC crack surface and the Ag-Si alloy nodules.

\section{Conclusions}

In summary, Vickers indentation impression and cracks in $\mathrm{SiC}$ could be healed by a vacuum heat treatment with $\mathrm{Ag}$ through a dissolution-reprecipitation mechanism. At high temperature, liquid $\mathrm{Ag}$ reacts with $\mathrm{SiC}$ to form carbon and an $\mathrm{Ag}-\mathrm{Si}$ alloy, followed by a reprecipitation process of $\mathrm{SiC}$. The newly-formed $\mathrm{SiC}$ grains healed the cracks and recovered the indentation impression. The recovery

\section{(a) crack}

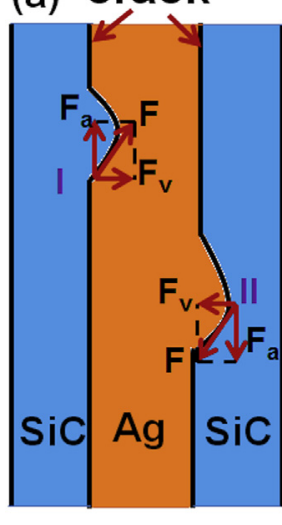

Initial state (b)

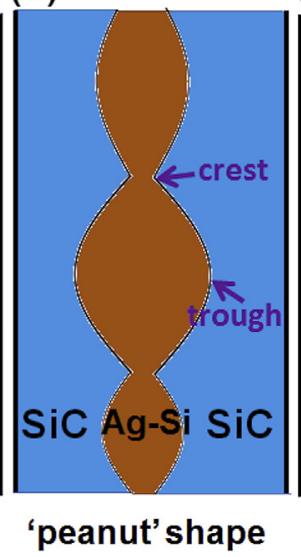

(c)

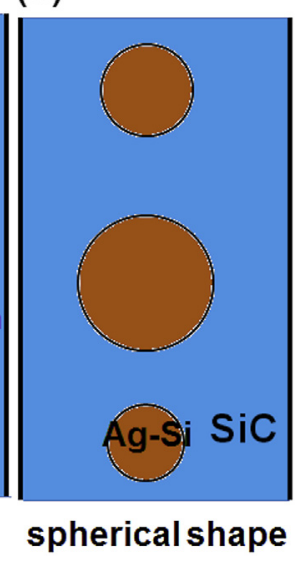

Fig. 10. Schematic illustration of the morphological evolution of the $\mathrm{Ag}-\mathrm{Si}$ alloy nodules with Rayleigh instabilities: (a) Initial state, 'perturbation'; (b) 'peanut' shape nodules of $\mathrm{Ag}-\mathrm{Si}$ alloys formed driven by the interfacial tension between $\mathrm{Ag}-\mathrm{Si}$ alloys and $\mathrm{SiC}$; and (c) final break up into rows of spherical $\mathrm{Ag}-\mathrm{Si}$ alloys nodules by minimizing the interface. 
ratio of the indentation impression is $\sim 60 \%$. A thermodynamic calculation confirms that the formation of $\mathrm{Ag}-\mathrm{Si}$ alloys accelerates materials transport in $\mathrm{SiC}$ in order to heal the damage areas at $1450{ }^{\circ} \mathrm{C}$. Moreover, a gradient in the SiC Gibbs potential between the flat surface and the concave surface (indentation impression) drives the newly-formed $\mathrm{SiC}$ grains to precipit inside the indentation impression by reducing the Gibbs energy of the SiC sample. A model based on the Plateau-Rayleigh instability theory is proposed to explain the morphological evolution of isolated $\mathrm{Ag}-\mathrm{Si}$ nodules by minimizing the interfacial energy between $\mathrm{SiC}$ and $\mathrm{Ag}-\mathrm{Si}$ alloys.

\section{Acknowledgment}

The authors would like to thank Professor B. Ralph for proofreading the manuscript. X. Geng wants to thank China Scholarship Council (CSC) for providing the funding.

\section{Appendix A. Supplementary data}

Supplementary data related to this article can be found at http:// dx.doi.org/10.1016/j.actamat.2015.11.052.

\section{References}

[1] L.L. Snead, T. Nozawa, Y. Katoh, T.S. Byun, S. Kondo, D.A. Petti, Handbook of SiC properties for fuel performance modeling, J. Nucl. Mater 371 (2007) 329-377.

[2] G. Liu, J. Li, Y. Shan, J. Xu, Highly dense $\beta$-SiC ceramics with submicron grains prepared by sintering of nanocrystalline powders, Scr. Mater 67 (2012) 416-419.

[3] R. Naslain, Design, preparation and properties of non-oxide CMCs for application in engines and nuclear reactors: an overview, Compos. Sci. Technol. 64 (2004) 155-170.

[4] F. Lange, Healing of surface cracks in SiC by oxidation, J. Am. Ceram. Soc. 53 (1970) 290, 290.

[5] J. Korouš, M.C. Chu, M. Nakatani, K. Ando, Crack healing behavior of silicon carbide ceramics, J. Am. Ceram. Soc. 83 (2000) 2788-2792.

[6] S.K. Lee, W. Ishida, S.Y. Lee, K.W. Nam, K. Ando, Crack-healing behavior and resultant strength properties of silicon carbide ceramic, J. Eur. Ceram. Soc. 25 (2005) 569-576.

[7] Y.W. Kim, K. Ando, M.C. Chu, Crack-healing behavior of liquid-phase-sintered silicon carbide ceramics, J. Am. Ceram. Soc. 86 (2003) 465-470.

[8] K.W. Nam, J.S. Kim, S.W. Park, The high temperature strength of SiC ceramics based on $\mathrm{SiO}_{2}$ nano-colloidal employed, Mat. Sci. Eng. A 527 (2010) 5400-5404.

[9] E.J. Opila, J.L. Smialek, R.C. Robinson, D.S. Fox, N.S. Jacobson, SiC recession caused by $\mathrm{SiO}_{2}$ scale volatility under combustion conditions: II, thermodynamics and gaseous-diffusion model, J. Am. Ceram. Soc. 82 (1999) 1826-1834.

[10] M. Mitomo, T. Nishimura, M. Tsutsumi, Crack healing in silicon nitride and alumina ceramics, J. Mat. Sci. Lett. 15 (1996) 1976-1978.

[11] A. Evans, E. Charles, Strength recovery by diffusive crack healing, Acta Metall. Mater. 25 (1977) 919-927.

[12] T.K. Gupta, Instability of cylindrical voids in alumina, J. Am. Ceram. Soc. 61 (1978) 191-195.
[13] D.L. Smith, B. Evans, Diffusional crack healing in quartz, J. Geophys. Res Sol. Ea. (1978-2012) 89 (1984) 4125-4135.

[14] W. Nakao, K. Takahashi, K. Ando, Self-healing of surface cracks in structural ceramics, Adv. Nanomater. (2010) 555-593.

[15] P. Greil, Generic principles of crack-healing ceramics, J. Adv. Ceram. 1 (2012) 249-267.

[16] J. Rödel, A.M. Glaeser, High-temperature healing of lithographically introduced cracks in sapphire, J. Am. Ceram. Soc. 73 (1990) 592-5601.

[17] T. Gupta, Kinetics of strengthening of thermally shocked $\mathrm{MgO}$ and $\mathrm{A}_{2} \mathrm{O}_{3}$, J. Am. Ceram. Soc. 59 (1976) 448-449.

[18] M. Hon, R. Davis, Self-diffusion of ${ }^{14} \mathrm{C}$ in polycrystalline $\beta$-SiC, J. Mat. Sci. 14 (1979) 2411-2421.

[19] M. Hon, R. Davis, D. Newbury, Self-diffusion of ${ }^{30} \mathrm{Si}$ in polycrystalline $\beta-\mathrm{SiC}$, J. Mat. Sci. 15 (1980) 2073-2080.

[20] J. Hong, R.F. Davis, Self-diffusion of carbon 14 in high-purity and N-doped $\alpha$ SiC single crystals, J. Am. Ceram. Soc. 63 (1980) 546-552.

[21] J. Hong, R.F. Davis, D. Newbury, Self-diffusion of silicon-30 in $\alpha$-SiC single crystals, J. Mat. Sci. 16 (1981) 2485-2494.

[22] S.I. Nakashima, H. Harima, Raman investigation of SiC polytypes, Phys. Status Solidi A 162 (1997) 39-64.

[23] Z. Feng, A. Mascarenhas, W. Choyke, J. Powell, Raman scattering studies of chemical-vapor-deposited cubic SiC films of (100) Si, J. Appl. Phys. 64 (1988) 3176-3186.

[24] D. Olego, M. Cardona, Pressure dependence of Raman phonons of Ge and 3CSiC, Phys. Rev. B 25 (1982) 1151.

[25] Z. Feng, Second order Raman scattering of cubic silicon carbide, Sci. Access 2 (2004) 242-243.

[26] J. Burton, L. Sun, F. Long, Z. Feng, I. Ferguson, First-and second-order Raman scattering from semi-insulating 4H-SiC, Phys. Rev. B 59 (1999) 7282.

[27] G. Chollon, J. Vallerot, D. Helary, S. Jouannigot, Structural and textural changes of CVD-SiC to indentation, high temperature creep and irradiation, J. Eur. Ceram. Soc. 27 (2007) 1503-1511.

[28] A.C. Ferrari, J. Robertson, Raman Spectroscopy in Carbons: From Nanotubes to Diamond, Royal Soc., 2004.

[29] W. Ni, Y.T. Cheng, D.S. Grummon, Recovery of microindents in a nickeltitanium shape-memory alloy: a "self-healing" effect, Appl. Phys. Lett. 80 (2002) 3310-3312.

[30] W. Huang, J. Su, M. Hong, B. Yang, Pile-up and sink-in in micro-indentation of a NiTi shape-memory alloy, Scr. Mater 53 (2005) 1055-1057.

[31] G. Sawyer, T. Page, Microstructural characterization of "REFEL" (reactionbonded) silicon carbides, J. Mat. Sci. 13 (1978) 885-904.

[32] R.N. Ghoshtagore, R. Coble, Self-diffusion in silicon carbide, Phys. Rev. B 143 (1966) 623.

[33] X. Geng, F. Yang, N. Rohbeck, P. Xiao, An original way to investigate silver migration through silicon carbide coating in TRISO particles, J. Am. Ceram. Soc. 97 (2014) 1979-1986.

[34] R. Olesinski, A. Gokhale, G. Abbaschian, The Ag-Si (silver-silicon) system, J. Phase Equilib. 10 (1989) 635-640.

[35] V.S. Robinson, S.K. Tarby, Thermodynamic properties of liquid Ag-Si alloys, Metall. Trans. 2 (1971) 1347-1350.

[36] R.W. Balluffi, S. Allen, W.C. Carter, Kinetics of Materials, John Wiley \& Sons, 2005.

[37] R.H. Bruce, Science of Ceramics, in: G.H. Stewart (Ed.), British Ceramic Society Conference, London, 2, 1965, p. 359.

[38] T. Gupta, Crack healing in $\mathrm{Al}_{2} \mathrm{O}_{3}, \mathrm{MgO}$, and related materials, Adv. Ceram. 10 (1984) 750.

[39] C. Yen, R. Coble, Spheroidization of tubular voids in $\mathrm{Al}_{2} \mathrm{O}_{3}$ crystals at high temperatures, J. Am. Ceram. Soc. 55 (1972) 507-509.

[40] J.W. Strutt, L. Rayleigh, On the instability of jets, Proc. Lond. Math. Soc. 10 (1878) 4-13. 